\title{
Pode a gestação influenciar a evolução de nódulo tireoidiano maligno?*
}

\author{
Can pregnancy influence the outcome of a malignant thyroid nodule?
}

\author{
Lucy Kerr $^{1}$, Maria Edith Lutz Vidigal ${ }^{2}$, Deborah Rozenkwit ${ }^{3}$
}

Resumo Os autores descrevem um nódulo tireoidiano com padrões ultrassonográfico e citopatológico benignos que diminuiu mais de $50 \%$ em três anos e se modificou durante a gestação, constatando-se que era carcinoma papilífero. Concluise que a gestação pode aumentar o risco de malignização ou acelerar o crescimento de nódulo tireoidiano maligno preexistente, corroborando dados da literatura.

Unitermos: Gestação; Câncer; Tireoide; Carcinoma; Papilífero.

Abstract The authors report the case of a patient with a thyroid nodule with benign sonographic and cytopathological features that had presented a decrease of more than $50 \%$ in three years and changed its pattern during her pregnancy, being diagnosed as papillary carcinoma. It was concluded that pregnancy can either increase the risk for malignant transformation or accelerate the growth of a malignant thyroid nodule, corroborating pre-existing literature data.

Keywords: Pregnancy; Cancer; Thyroid; Carcinoma; Papillary.

Kerr L, Vidigal MEL, Rozenkwit D. Pode a gestação influenciar a evolução de nódulo tireoidiano maligno? Radiol Bras. 2012 Jan/Fev; 45(1):65-66.

\section{INTRODUÇÃO}

É descrito que o câncer tireoidiano agrava-se durante a gestação ${ }^{(1-3)}$ e o pior prognóstico estaria relacionado ao fator de crescimento mediado pelo receptor estrogênico alfa, cuja expressão está aumentada nos tumores tireoidianos que cursam com a gestação $^{(\mathbf{1})}$.

O caso ora relatado mostra um nódulo tireoidiano acompanhado antes, durante a gestação e na lactação, o qual reduziu 58\% no seu volume em relação ao exame inicial, quando apresentava citopatologia e ultrassonografia (US) benignas ${ }^{(4)}$. Os aspectos ultrassonográficos sugestivos de malignidade só surgiram durante a gestação e lactação, quando foi repetida a punção aspirativa com agulha fina (PAAF) e diagnosticado como carcinoma papilífero. Neste

\footnotetext{
* Trabalho realizado no IKEP-Instituto Kerr de Ensino e Pes quisa, São Paulo, SP, Brasil.

1. Médica Ultrassonografista, Diretora do IKEP-Instituto Kerr de Ensino e Pesquisa e da Sonimage, São Paulo, SP, Brasil.

2. Médica Endocrinologista, Membro da Sociedade Brasileira de Endocrinologia, São Paulo, SP, Brasil.

3. Médica Clínica Geral, Estagiária em Ultrassonografia no IKEP-Instituto Kerr de Ensino e Pesquisa, São Paulo, SP, Brasil.

Endereço para correspondência: Dra. Lucy Kerr. Avenida Brigadeiro Luís Antônio, 2504, $2^{\circ}$ andar, conjunto 21/22, Jardim Paulista. São Paulo, SP, Brasil, 01402-000. E-mail: lucykerr@ lucykerr.com.br

Recebido para publicação em 12/12/2010. Aceito, após revisão, em 11/8/2011.
}

relato, o acompanhamento evolutivo do caso foi fundamental para a detecção da mudança do padrão morfotextural e do Doppler, sugerindo a malignidade da lesão e possibilitando a conduta adequada.

\section{RELATO DO CASO}

Paciente de 31 anos de idade descobriu, ocasionalmente, nódulo tireoidiano, cuja primeira PAAF, de 9/8/2005, diagnosticou lesão cística hemorrágica benigna. Exame ultrassonográfico de 3/11/2005 revelou nódulo misto do lobo esquerdo (Figura 1 ) de padrão benigno, medindo $1,2 \times 0,8 \times$ $0,6 \mathrm{~cm}$ nos diâmetros longitudinal, transversal e anteroposterior, cuja parte cística apresentava nível líquido-líquido, o que sugeria estratificação de densidades, como na mistura óleo-água, frequente na hemorragia intranodular. $\mathrm{O}$ estudo com Doppler mostrou um único vaso penetrando a vegetação (Figura 2). Nova US, em 6/10/2006, revelou diminuição de $33 \%$ no volume nodular por reabsorção líquida parcial, mas a parte sólida permaneceu inalterada.

Exame ultrassonográfico de 4/11/2009, na $22^{\mathrm{a}}$ semana gestacional (Figura 3 ), revelou diminuição nodular de $36 \%$ por reabsorção da parte cística, mas a vegetação triplicou de volume e hipervascularizou-se, sendo ambos estes sinais suspeitos de malignidade $^{(\mathbf{1}, \mathbf{4 , 5})}$. Indicou-se segunda PAAF do nódulo tireoidiano direcionada por US, realizada em 23/4/2010, que sugeria duas hipóteses: hiperplasia pseudopapilífera em bócio adenomatoso ou carcinoma papilífero. Exame ultrassonográfico realizado em 10/5/2010, 40 dias após o parto, constatou que o nódulo tireoidiano havia aumentado 2,3 vezes em seis meses, estava totalmente sólido, mal delimitado, hipoecogênico e com microcalcificações, sugerindo malignidade $^{(4)}$ (Figura 4). Foi realizada cirurgia em 20/5/2010, que diagnosticou carcinoma papilífero de padrão clássico encapsulado, de $0,5 \mathrm{~cm}$, estadiamento T1A.

\section{DISCUSSÃO}

A PAAF e a US inicial classificaram o nódulo tireoidiano como benigno, mas era maligno quando operado após três anos, embora a presença de vaso único na região central da nodulação no estudo Doppler inicial seja considerada suspeita de malignidade por alguns autores ${ }^{(\mathbf{6}, 7)}$. Entretanto, outros autores só consideram o padrão Doppler maligno se totalmente hipervascularizado $^{(\mathbf{4 , 5}, \mathbf{8})}$, e o consenso de 2008 indica PAAF para investigar esses nódulos ${ }^{(5)}$. Duas hipóteses se impõem neste caso: ou 


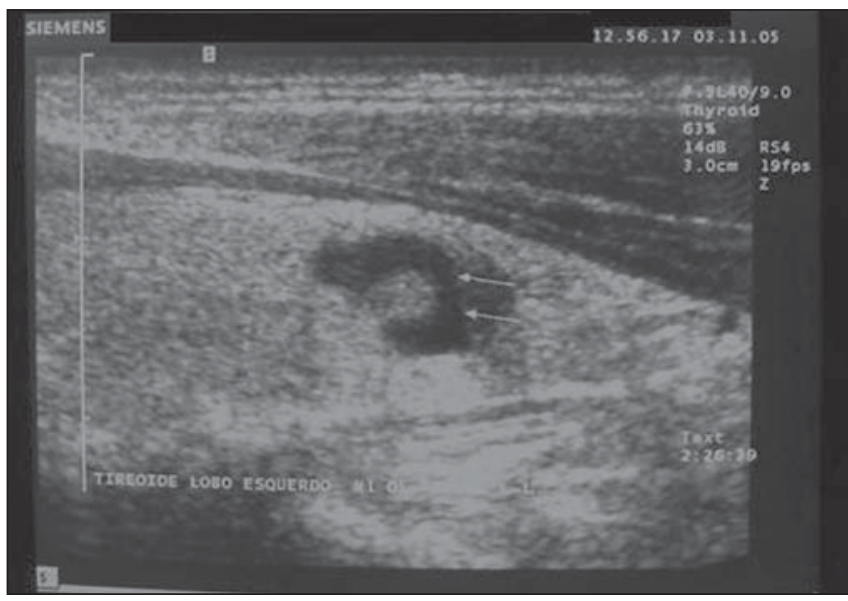

Figura 1. Primeiro exame ultrassonográfico (3/11/2005) mostra nódulo misto do lobo tireoidiano esquerdo de padrão morfológico benigno, com parte cística apresentando estratificação de densidades, como na mistura óleo-água, frequente na hemorragia intranodular.

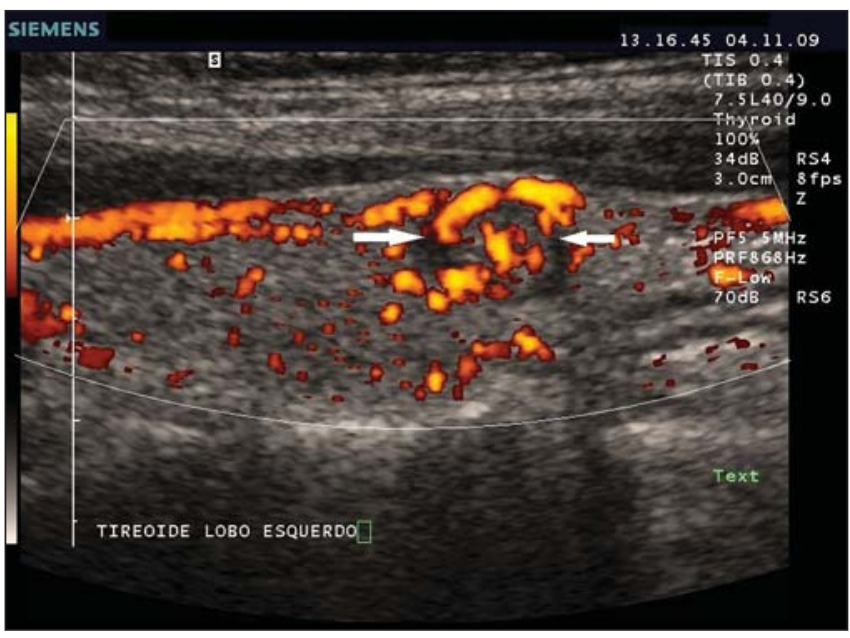

Figura 3. Vigésima segunda semana de gestação. Nódulo do lobo tireoidiano esquerdo em corte longitudinal, com hipervascularização da parte sólida (setas).

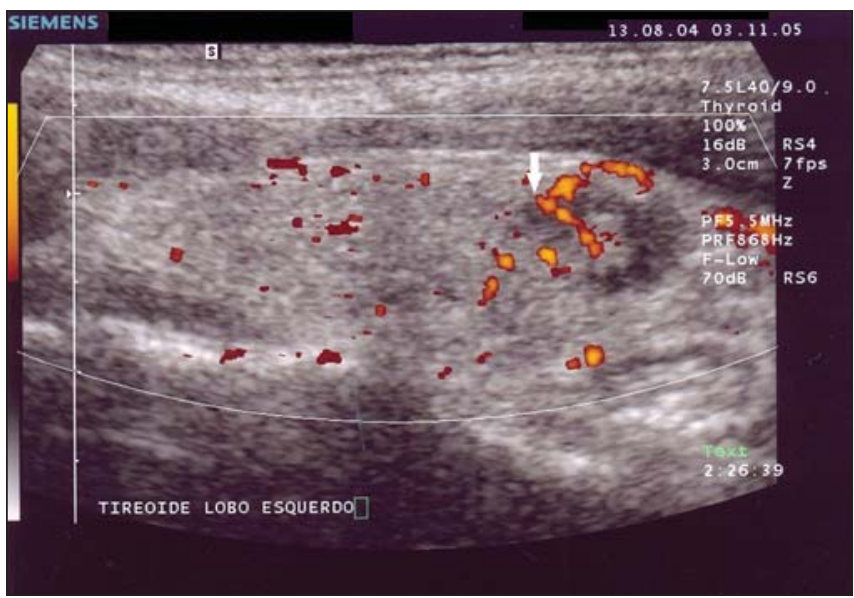

Figura 2. Estudo por Doppler do nódulo do lobo tireoidiano esquerdo mostra vaso penetrando a vegetação sólida (seta), caracterizando-a como tecido vivo (exclui coágulo sanguíneo).

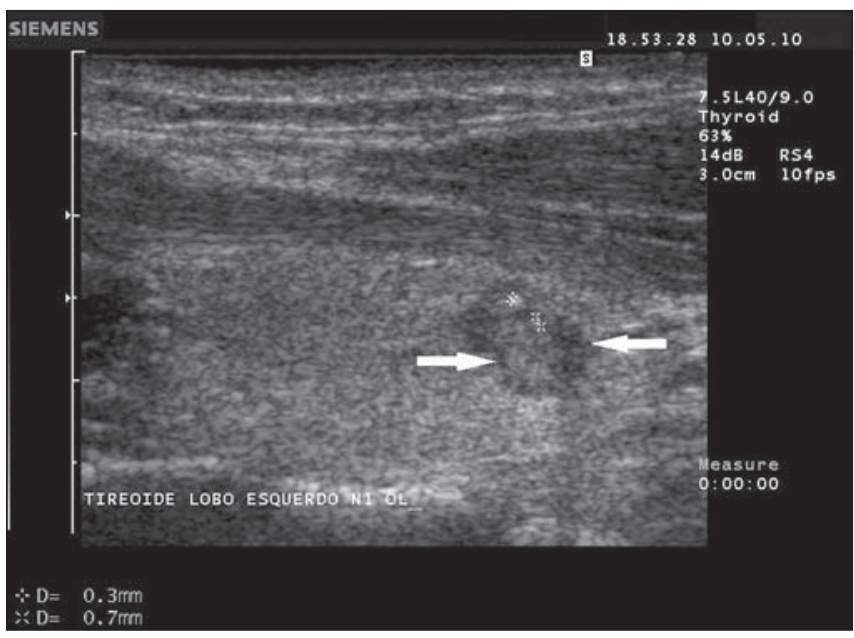

Figura 4. Quarenta dias após o parto, o nódulo do lobo tireoidiano esquerdo (setas) está totalmente sólido, mal delimitado, hipoecogênico e com microcalcificações (calipers) o nódulo era benigno e malignizou-se ou sempre foi maligno (falso-negativo da PAAF e US), acelerando seu crescimento durante a gestação. Observa-se que o nódulo reduziu $58 \%$ entre a primeira e a terceira US, reabsorveu o conteúdo líquido e surgiram sinais suspeitos: triplicação do tamanho e hipervascularização da parte sólida. É mais provável que já havia malignidade desde o princípio e que a gestação tenha contribuído para o crescimento acelerado do nódulo. A análise evolutiva à US permitiu suspeitar a malignidade, corroborada pela PAAF. Conclui-se que a gestação pode ter influenciado o crescimento de nódulo maligno preexistente e que o seguimento evolutivo foi fundamental para o diagnóstico correto deste caso.

\section{REFERÊNCIAS}

1. Vannucchi G, Perrino M, Rossi S, et al. Clinical and molecular features of differentiated thyroid cancer diagnosed during pregnancy. Eur J Endocrinol. 2010;162:145-51.

2. Vini L, Hyer S, Pratt B, et al. Management of differentiated thyroid cancer diagnosed during pregnancy. Eur J Endocrinol. 1999;140:404-6.

3. Wémeau JL, Do Cao C. Thyroid nodule, cancer and pregnancy. Ann Endocrinol (Paris). 2002;63:43842.

4. Kerr L. High-resolution thyroid ultrasound: the value of color Doppler. Ultrasound Q. 1994;12:2143
5. Cibas ES, Alexander EK, Benson CB, et al. Indications for thyroid FNA and pre-FNA requirements: a synopsis of the National Cancer Institute Thyroid Fine-Needle Aspiration State of the Science Conference. Diagn Cytopathol. 2008;36:390-

6. Chammas MC, Gerhard R, Oliveira IRS, et al. Thyroid nodules: evaluation with power Doppler and duplex Doppler ultrasound. Otolaryngol Head Neck Surg. 2005;132:874-82.

7. Lagalla R, Caruso G, Novara V, et al. Analisi flussimetrica nella patologia tiroidea: ipotesi di integrazione con lo studio qualitativo con color-Doppler. Radiol Med. 1993;85:606-10.

8. Faria MAS, Casulari LA. Comparação das classificações dos nódulos de tireoide ao Doppler colorido descritas por Lagalla e Chammas. Arq Bras Endocrinol Metab. 2009;53:811-7. 